\title{
Spud: A Structured Methodology For The Design Of Web Sites
}

Thomas A. Slivinski, (E-mail: tslivin@american.edu), American University Francis D. Tuggle (E-mail: ftuggle@american.edu), American University

\begin{abstract}
The World Wide Web (web) grows apace, yet many web sites possess a confusing design, frustrat-

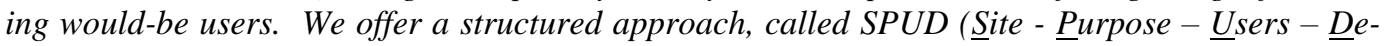
sign) to the task of designing, not implementing, web sites. Our methodology focuses upon a structured walkthrough of a web site and consists of three phases (and 15 substeps), with possible iteration between the stages. (1) Define the audience characteristics of users of the web site, including their motives for visiting, their demographics, and their likely technological capabilities. (2) Plan accordingly the structure of the web site, the page layouts, and the navigation procedures between pages. (3) Develop and test functions useful to the users of the web site, such as a search function (for a complex web site) or an order function (for a retail web site).
\end{abstract}

\section{Introduction}

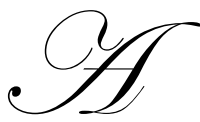

recent study by the Boston Consulting Group and shop.org (see Betts, p. 8) is that only about 3\% of web site visitors actually buy anything and that about $65 \%$ of shopping carts are abandoned before the purchase. While it is doubtlessly true that some visits are for information and exploration only, since many web sites are confusing and awkwardly laid out, improving the design of web sites might go a long way toward alleviating those dismal statistics. Wannacott (2001) reports the average download time of an eshopping site is around 23 seconds, long enough to try the patience of anyone. In fact, Fleming (1998, p. 30) reports that pretty consistently, the top irritants most users experience surfing the Internet are (in descending order) delays/speed, lack of trust, dead ends, easy to get lost, need for plug-ins, and hard to read.

We offer in this paper a three-phase methodology for the efficient and effective design of web sites, a methodology we call SPUD for Site--Purpose--Users--Design as a mnemonic for the four key considerations behind successful web site design. (The methodology is intentionally entitled SPUD partly to convey our sense that this is a "down to earth" methodology; it is intended to be of immediate assistance to web designers.) In a sense, the SPUD methodology is an expanded, systematized and structured version of Blakey's (2000) "walkthrough" to verify that the web site functions from the visitor's point of view, not the site owner's. It draws from Rosenfeld \& Morville's (1998) concepts for using an integrated information architecture in implementing web sites. The methodology is top-down. As Powell (1998) observes, neither the traditional waterfall nor JAD (joint application development) methodology is ideal for web site development, though SPUD incorporates useful aspects of each approach, along with the iteration inherent in the spiral model. A companion paper, Tuggle and Slivinski (2001), reports upon the application of SPUD to the design of web sites for three very different firms to illustrate the methodology in use.

We begin with defining the site's purposes and audience and continue through the design. SPUD entails 15 substeps inside the three phases. See Table 1 for an overview of the three phases and 15 steps. Because "downstream" discoveries may call for refining--and redoing--"upstream" decisions, our methodology is inherently iterative. Further, SPUD is a design methodology. It does not include the actual implementation or operation of a web site nor the alternatives available for implementation and operation.

Readers with comments or questions are encouraged to contact the authors via email. 
We have induced these rules of thumb from teaching and grading literally hundreds of undergraduate and graduate students in the process of web site design (through two projects--a simple personal web site and a more complicated eCommerce web site). These rules are also based upon our personal experiences surfing in cyberspace for informational, personal, business, professional, educational, and research purposes, as well as reading the literature. Of course, we ourselves have been webmasters for a variety of personal and professional web sites.

The SPUD web design methodology was developed to assist web authors in setting up and designing a "good web site." This structured methodology has been developed to provide the site designer with a natural procedure that will result in a better design the first time and provide the basis for identifying and implementing improvements. The methodology is highly intuitive and has application for both the neophyte designer and the seasoned professional. The SPUD methodology encompasses three phases: Define the site, Plan its structure, and develop the enabling infrastructure.

Before we start, the term "good web site" needs some definition: A site can be "cool" or "hot" or even "professional" looking without accomplishing the intended purpose or mission. In the context of this methodology, we will call a site "good" if it satisfies its intended purposes. What are its intended purposes? How do we determine if it does satisfy them? That is the basis of the first phase in the SPUD Web design methodology.

Finally, one person alone should not undertake the SPUD methodology. For best results, a team should perform the methodology. Sano (1996, p. 9) recommends a team consisting of representatives from the computer programming field (for implementation expertise), the visual design field (for graphics expertise), the field of editing and writing (for expertise with documents, searching, and hypertext), and the marketing field (for expertise at identifying and exploiting opportunities). To this list we would cheerfully add end-user representatives.

\section{Phase I - Define the site, its purpose, and its audience}

\section{Step 1: Review the competition}

Identify several (at least three) competitors or other organizations that provide similar goods, services or content and access their web sites. Rosenfeld and Morville (1998) point out that "it is much easier to express gutlevel likes and dislikes about particular sites than to talk abstractly about aesthetic and functional preferences." Perform a basic analysis of these sites to determine what their site actually does, whom it is targeted at and how well it operates. Note that we suggest that this be done before you settle on the final purpose or scope of your own site. It's a good rule of thumb - If none of your competitors are doing something, then you should take great care in being the first.

After the initial review, go back and perform a more detailed review of each site - specifically look at the site's general layout, navigation techniques and special functions. Record your impressions of the site page by page. What do you like about it? What irritates you? What features do you wish it offered? (Better yet, get some people who are part of the site's target audience to look at the site and record their impressions of the site, page by page, by taking a verbal protocol as they surf the site.) Record the colors, graphics, animation and use of any special features - sound, video, etc. If something catches your eye, record that information. Consider the ease and/or difficulty of moving from page to page. Rosenfeld and Morville (1998, pp. 4-6) report that typical dislikes of web sites include the inability to easily find desired information, poor graphic design and layout, gratuitous use of bells and whistles, an inappropriate tone (e.g., jargon), designer-centeredness, pages under construction, and lack of attention to detail. See also www.webpagesthatsuck.com.

After you have acquainted yourself with the general design and layout of the site, perform several common functions that you expect your users to perform on your site and record the results as a benchmark for your site. For example, if you are designing an eShopping site, you might choose a common item and step through the ordering process - locating the item, selecting the desired features, building a shopping basket, etc. You might additionally choose a "hard to find" item or one that is very specific to size, color, style, etc. At a minimum, keep track of the following statistics: the number of pages that you must search through to accomplish your task, the amount of time 
that you waited for each page to load, and the amount of time that you had to spend locating the next link on a particular page. These three parameters will provide some measure of the usability of the site. These parameters should also provide some of the initial design metrics that your site must meet or exceed.

"A white paper by Zona Research, Inc. attempts to quantify the economic loss due to unacceptably slow web page download speeds, which is one aspect of e-business customer churn. As of the April 1999 paper, they estimate as much as $\$ 362$ million is lost per month from customer bailout, and this study only addresses bailout from impatience." (Freshtech.com)

\section{Step 2: Precisely define your mission and objectives:}

A good design for an eShopping site will be quite different from the design of a portal. For the purposes of this discussion, a web site will be considered "good" if it meets its intended purposes. That being said, it then befalls the designer to define the intent, purpose and measurable outcomes of the site under design. This sounds trivial, but is very significant. The old saying "when you don't know where you are going, any road will get you there" holds true in web design as in any other endeavor. Nielsen (1999) reminds us that users want answers, not glitz or lofty statements of purpose.

Note that there is no requirement that your site have one home page and that all users automatically are linked to that page. In fact, if you develop any relatively complex site, remember that one of the powers of the web is your ability to customize a page to a specific purpose, audience or product line. Therefore, don't be concerned if you identify several seemingly contradictory objectives or audience-objective combinations.

Some examples of site objectives:

- We need it as a class project - this is the usual reason that students start their own web page. They have to have the web site to meet the teacher's demands. The teacher is their audience and the metric is their grade.

- Our competitors are doing it -- web presence is growing and when you find that your competitor has a web site, many businesses automatically decide to implement one. If that is your case, use your competitor's site as a roadmap and save time and money.

- $\quad$ Corporate Image -- many organizations view the web as enhancing their image to clients (and potential clients), competitors, and prospective employees.

- $\quad$ Recruitment - most corporate web sites these days have listing of openings and actively solicit responses from prospective employees.

- Direct Sales - this is eShopping and the items are sold directly from the web. Items can range from hard physical goods to services, from aardvarks to zithers. Structurally, most successful eTailing operations sites have multiple pages each specifically designed as an entry point to a different client base (the ease of creating new pages facilitates this) and have direct customer payment via credit card. Most also offer other functions (search, background information, etc.) to attract viewers.

- $\quad$ Prospect List -- we are mining for qualified prospects.

\section{Step 3: Define your audience and their intended outcomes for accessing your site}

Specify, as clearly as you can, the intended audience of your web site. Audience should be defined by common demographics - age, sex, income level, special interests, physical location, education, national origin and language spoken, occupation, etc., and differentiated by intended outcomes. Claritas PRIZM clusters the US population into 62 groups (see their web site for a description of each of the clusters). That URL offers a great starting point in defining the specific demographics of your intended audience and serves as a checklist of factors to consider in defining your audience. Fleming (1998) provides an overview of sample audiences and their interests.

Nielsen (1999) claims that most customers know what they're looking for and therefore a prominent search bar is a vital feature. He also notes that many customers go to a web site to look for an address or telephone num- 
ber, so those data also need to be conspicuous.

Note, however, that the intended purpose of your web site may be different for different audiences. This may mean that you design multiple entry points into your site for different user groups. Also, don't make the mistake of assuming that the demographics for your site will be the same as the demographics for a brick and mortar establishment. Studies of sites such as www.sears.com have shown that customer demographics are significantly different for the web site than for the store.

For example, if you are developing a site to sell children's toys, you have at least two different audiences with different intended outcomes to consider:

- $\quad$ Children (age range? gender?) drawn to the site (metric - the number of children's eyeballs) and persuade them to want your product.

- $\quad$ Grandparents and parents (demographic definition?) who order the product for the children (metric -- the number of orders) provide an easy way to identify, order and pay for items.

For the child, the site must be exciting, intuitive and easy to navigate. Use of animation, color and other factors to attract children become very important. Having an online game (or a story whose content changes over time) at the site will not only attract children, it will keep them at the site and it will cause them to refer the site to their friends. Such viral marketing can vastly extend the reach of the site. However, extended use of such features (animation, color, graphics, stories, games, etc.) slows the downloading of the site and increases the chance that real buyers will be put off. For the adults, a streamlined on-line order entry process with minimal delays is required.

Another approach for quickly capturing informational needs of a user population is described by Broadbent and Cara (2000). Their procedure involves gathering a set of "life stories" and interpreting the resulting narratives.

Fleming (1998) advises you to "put yourself in the user's shoes." The user's goals (purchase securely, retain privacy) may be the exact opposite of the company's goals (rush people to the shopping cart, find out all it can about the customer). One needs to understand the web site from the user's perspective.

She goes on to provide navigational guidance for the design of six different types of web sites: shopping, community, entertainment, identity (i.e., understanding what a company does or what types of students a university has), learning, and information (i.e., providing reference or news material).

\section{Phase II - Plan the concept of operations of the site}

Step 4: Define major tasks that users will perform on your site

This task list should include all of the normal functions that you will want all users to be capable of performing when they go to your site. The more tasks that you can identify that users actually desire the better that your site design will be. It is often helpful to enlist the aid of others not so familiar with your project, to get fresh ideas on tasks. Outsiders may provide insights into what real clients/users will demand. Common tasks include:

\footnotetext{
- $\quad$ Ordering an item;

- $\quad$ Getting information about an item;

- $\quad$ Finding related items;

- $\quad$ Finding out about an existing order;

- $\quad$ Getting questions answered;

- $\quad$ Asking for additional information;

- $\quad$ Enrolling or subscribing to a service;

- $\quad$ Playing a game;

- $\quad$ Reading a continuing story or other form of content;

- Locating an item or piece of information.
} 
Rosenfeld and Morville (1998, pp. 99-130) note the importance of designing search functions carefully (is the user looking for one item, the existence of items, or all items?) as well as how results of searching are displayed to users. How much information is reported back? How is it sorted and ordered? Should relevance ratings be reported?

\section{Step 5: Identify which audiences will perform each task.}

General audiences may be satisfied with generic information (e.g., services offered and pricing). "Registered" customers may need immediate access to firewall-protected information (e.g., tracking data for a delivery firm). "Platinum" customers may need an immediate telephonic connection to a human service agent (e.g., a customer with an unusual request or problem) or some other high-priority service.

To return to the example of the children's toy site, it is unlikely that children would want access to the ordering function, and it is unlikely that adults would want access to the online game or story. Consequently, those subsites can be designed to optimize the experience of the expected viewers. Note: there is nothing that would bar children from reviewing the ordering function or that would bar the adults from accessing the online story, but each would be expected to have fairly uncomfortable experiences at those subsites.

\section{Step 6: Prioritize your tasks.}

Prioritize the tasks in terms of their importance to your audiences and your reasons for establishing the site. You want to make it easiest for your viewers to accomplish their highest priority tasks with the least number of clicks and scrolls.

\section{Step 7: Perform a task analysis on your most critical tasks}

Task analysis metrics quantify the individual tasks that a user must perform to accomplish their intended purpose. Typically, tasks differ from site to site depending on the intent of the user. For example the buyers in our children's site must accomplish 6 tasks - go to the home page; locate the item for purchase; create a shopping cart; add the item to their shopping cart; close out the shopping cart; and purchase the item. (All 6 functions do not have to be completely performed each time for each user. A user who accesses the site multiple times to buy different items at different time can short circuit some steps if the system uses a personal identification system or something similar.) A potential buyer who quits after completion of one or more tasks should be a major source of concern. One should keep statistics on abandonment rates and identify where in the task sequence abandonment tends to occur. Knowing that, one can then strive to simplify the process to minimize abandonment.

Each task should be viewed in terms of the time required for the task to download, the amount of information that the user must supply (number of entry fields and the number of characters of data) and the method of input.

\section{Step 8: Define what will get users to your site, what will keep them there and what will get them to return.}

These three factors will generally be different for different target audiences. We deal with the latter two here since they are design issues related to the content of the site. The first issue is a global issue and is covered in the next step.

Viewers remain or return to a site based on its content. They stay on site because the site offers something that attracts them: something to do, something to read or view or do, something to listen to or see, or something to help them make a better buying decision. You must determine what content your site will have to capture and keep viewers. It is also important to recognize that just offering the best critical task implementations will not work to keep viewers at your site. You must add value to the viewer's experience. Remember that the average viewer's attention span is short - studies show that the average viewer stays on a page for about 50 seconds (American Demographics present a set of marketing tools that can be used by information-based marketers).

Content can be divided into three categories - content required to perform the specific critical tasks of the 
site, content peripheral to the specific critical tasks but of related interest, and unrelated content that is provided as a viewer service. For example, at an eShopping toy site, the product catalog, order forms, credit card processing and order tracking functions are specific to the critical task. Related content can include an online game, a story with content that changes over time (e.g., subsequent chapters or episodes), information on toy safety, consumer response to items, third party recommendations, tie-in information, links to related sites, ideas for selecting toys based on a child's demographics, a video on how to assemble an elaborate toy (e. g, a bicycle or a kitchen set), etc. Unrelated viewer service content usually includes links to non-related sites, downloadable wallpaper, email and the like.

As a general rule, do not add unrelated service content to your site (unless you receive a commission for each viewer who clicks through your site to another site). Related content information offers the best payoff. Consider use of advice/ tips, active message boards, new product highlights and reviews as ways to extend viewership. One technique to consider is the use a regular expert column to deal with viewer concerns and questions, issues of interest to viewers (such as toy safety), and to provide interviews with personalities in the field. Don't forget that content must be refreshed regularly with new photographs, news, tips, etc.

For each audience group, you should define the specific content that will attract that viewer group to your site. Note that the content may be of interest to multiple viewer groups. Consider what content your competitors offer. Your viewers will expect as much from you.

\section{Step 9: Define where your audience will come from.}

The flexibility of the web allows us to consider several different methods for attracting users to a site. In preparing your analysis, you need to develop the basic sources of customer links to your site. Where are they coming from and how did they learn about your site?

Customer sources generally come from four sources: normal advertising (we all saw the ads for Pets.com and eToys.com); word of mouth (yes there is a great chat room of potential users who will talk up or down any site); paid advertising click throughs (we have all seen these banner ads and other links on portals and other "free" content services); and search engines. It is not the intent of this paper to rate any of these potential sources. It is important for you to identify how you will attract viewers to your site. It makes a difference in the design. For example, there are many different techniques for working with search engines. Each major search engine has its own techniques for sorting out which URLs it supplies and in what order for any specific query term(s). If you are going to rely on search engines, get a specialist to help you with meta tags, key word summaries, phantom link pages and the like.

\section{Step 10: Define your success metrics}

Knowing your objective, tasks and target audience are not sufficient - you also need to have some way to measure progress - how close to achieving your results did you come? You need metrics - specific items that you can count will tell you whether or not you have succeeded. "In most cases, the measurement will be closely related to the goal or purpose of the site" (Powell, 1998).

We suggest three types of metrics. The first type are basic design criteria metrics for critical tasks. These metrics should flow from your review of the competing sites. The idea is that your site should be "more user friendly" than the competitor's. The metrics should include:

1. Maximum number of pages accessed to perform a required task;

2. Amount of time that average users must wait for each download (use the communications capability and time of day that you believe your audience will actually access your site - for public access, we still use $56 \mathrm{~kb}$ modems, for other users, the rates can vary);

3. Amount of time that user must spend locating the next link;

4. Amount of information that the user must input to accomplish the most critical tasks.

The second type of metric is the operational metric. Operational metrics are statistics on the number of viewers who come to your site, where they come from, the number that actually order the item, the number that be- 
gin ordering and then bail out and so forth. Most successful sites review server access logs to determine the profile and patterns of their site traffic. You will need to look at where people are going in your site, where they're NOT going, what pages they enter into and what pages they leave from. We recommend the following as a barebones set of initial operational metrics:

- $\quad$ Total average, min and max number of site visitors per day;

- $\quad$ Daily average, min and max number of visitors for each planned access point into your site;

- $\quad$ Daily average, min and max number who initiate critical functions;

- $\quad$ Daily average, min and max number who complete critical functions (did not bail out);

- $\quad$ Daily average, min and max number who bail out at some critical intermediate point in your processes;

- Daily average, min and max number who come from sources (search engines/portals) that you have counted on in your user attraction plan;

- $\quad$ Daily average, min and max number who come from other sources;

- $\quad$ Abandonment rates for your site, plus information on where the users were when they abandoned the ordering function.

(Note: if you are using search engines, you will have to develop a set of terms or keyword expressions for the search engines.) It is very important to determine what search expressions were actually used in linking the user to your site. Further, it is well known that most users don't read more than one page of output from a search engine without changing search parameters or going elsewhere. Free software exists which will tell you for all of the most popular search engines where your site turns up for specific search terms. If you are counting on the search engine attracting viewers and you are lower than 10 , forget about it.)

The third type of metric is demographic metrics - getting as much information on viewers as possible (other than their point or origin and departure). There are no foolproof ways to determine the demographics of your site visitors. Techniques that you can use to project demographic include surveys, focus groups, and interviews with potential site visitors to determine who will use your site. Another technique is to embed requests for audience demographic information into your site. Allow a user to tell you his/her age, gender, education, job, etc. The problem with embedding audience questionnaires into your site is that they will put off a certain portion of your audience as being intrusive and the persons who actually complete the information do not always reflect a cross section of the viewers.

\section{Phase III - Develop your site}

Before we start on the actual design of your site, there are several important facts about the effects of different hardware and different software on how web sites appear to the user that need to be understood.

- $\quad$ First, you cannot control what each viewer will see on the web. Each person views your site using his/her own operating system and own browser - Netscape Navigator or Microsoft's Internet Explorer are the two most common -- and there are significant differences between these two products. There are often unpredictable interactions between operating systems and browsers. The browser used will affect the way the viewer will see your page and the way that the layout of your web site is treated. Your design is really a template that is interpreted by these browser programs.

- $\quad$ Second, there are difference between different versions of the same browsers - Netscape and Microsoft have added new features into their browsers with each version. If your design incorporates the "latest" browser features, you may be precluding a large class of viewers with only older versions of the browser from your page.

- $\quad$ Third, browsers have settings that allow the viewer to customize such things as colors, fonts and character sizes for his browser. The same page may look very different to one viewer using Navigator with his colors set to yellow and black and very large heavy fonts than to another who uses much smaller fonts and the traditional colors.

- $\quad$ Fourth, the hardware that viewers employ in their monitors and graphics controllers affects what your page looks like. We all understand that the speed of the communications lines affects how long your page takes 
to download, but the size of the viewer's screen, its resolution, and the amount of information that it can handle affects how your page will look.

- $\quad$ Fifth, users may or may not have various browser add-ons or plug-ins enabled. Thus, audio files, video files, and animation may or may not appear on users' monitors.

- $\quad$ Sixth, different connection speeds to the Internet, ranging from low speed modem over telephone lines to high speed fiber optic cable, result in web pages being displayed quickly or slowly. If too slow, the user may abandon the site and go elsewhere.

- $\quad$ Seventh, as Sano (1996) points out, web viewing is very different from reading a book or magazine. "A book is generally linear in its organizational structure and viewed in various physical positions by the reader. The portable nature supports reading in a multitude of postures. The content is confined between the outer book covers, with an obvious beginning and end. The surfing activity is more likely to be fragmented and quick, rapidly clicking through pages, restlessly scanning 'chunks' of copy and images, then moving on, traversing web sites which dramatically differ in visual quality, colors, metaphors, navigation and content."

The rule to remember is that your design is only one of the parameters that affects what your viewers will see (or not see). Site design is from the top down. It follows a logical flow: First, work out the page structure, then overlay the navigation techniques, finally, worry about the actual layout and content of each page.

\section{Step 11: Prepare a list of pages and summary page descriptions.}

You should have one page from each critical task that your site must perform. For each page list the title, tasks performed, intended audience, functional content summary and required links to/from other pages. Each page should be no longer than two or three screen views (too much scrolling quickly discourages further surfing). Treat each page as a resource. Be particularly careful about your home page(s). Limit the information on these pages to those items essential for your purposes. Remember that your home page(s) are your windows on the world -keep them simple and direct. You can have multiple entry points (home pages) for different viewers - this allows you to streamline each home page to its own audience.

Segment items into as many subject-related pages as possible. Many items of information such as awards, resumes, facilities and other information are of interest to only a very small subset of viewers. Keep this kind of information off the home pages. Add links for those viewers who want this information but don't clutter your home pages with information that is not essential to the viewer. Keep first things first.

\section{Step 12: Create a site map.}

Your site map integrates the pages that you have defined in Step 1 into a graphic roadmap showing all of the linkages between pages. The roadmap should tell where you must be linked to perform each critical function. Count the number of pages that the viewer must access to perform each of the critical functions that you identified in the earlier phase. One of the goals of design is to minimize the number of such linkages. Your entire site should not be more than three or four levels deep (access to three or four pages to perform all functions) and all critical functions should be accessible in one or two levels.

Powell (1998, p. 149) observes that there is a tradeoff between the expressiveness of a site structure and the degree of confusion that it may engender. A linear structure is not confusing, but it is limited in its expressiveness. A completely random array of web pages is maximally expressive, but also opens the door widely to possible confusion on the user's part.

\section{Step 13: Prepare a general page layout format and schema for your site}

Before you design any specific pages you should design the general schema for your site. Shneiderman (1992) provides a comprehensive statement of issues and considerations when developing the interface that the user will interact with, ranging from the scheme for menu selection and form fill in to screen design issues. Wannacott 
(2001) proposes that one benchmark any e-shopping site against www.neimanmarcus.com along the dimensions of (in order) page design and layout, navigation, information architecture, and integrated functionality. A general schema is an overall framework for the look and feel of your pages. It includes the basic navigation facilities; the general page layout (headers, frames, etc.) and other parameters required to achieve consistency in your site. The most important elements of the general schema:

Basic Navigational System. There are several choices for a navigational system based on tabs, frames, buttons, tables, etc. The specific type of system that you select depends on personal taste and norms in your industry. (We are not aware of any studies that show one type of navigational system is better than any other type. Commonly, the navigational elements are grouped in a Navigation Bar or Panel.) In the early days of the web, the designer usually included a "click_here" as an indicator to the viewer of the navigational linkage. However, this practice is now frowned upon by many designers as unattractive. There are several general rules:

- $\quad$ First and foremost, the navigational scheme must be intuitive and consistent to allow the user to easily and quickly move to the desired page. This means that links must be located in the same place on the page with consistent titles, graphics or text. It is also important that the linkages be self-apparent and easily recognizable as such. If you are going to use graphical links, make sure that the graphics are very descriptive and use Alt Text Mouse Over Option to display text over the graphical link. If you are going to embed links into your pages, using a hyperlink border of 2 pixels helps to make the link more visible to the user.

- Users must always know where they are at any point in time. This means that the current page must be clearly identified. Techniques for this include the use of tabs or side navigational bars that highlight the current page.

- $\quad$ Other common techniques for visually assisting the viewer are separating the link texts from each other with lines or borders, adding some graphics (such as bullets or triangles or other icons) to the linkage line, and making the buttons appear raised above the surface.

- If your site is large (more than 6 or 8 pages) or requires the user to traverse more than 2 levels to reach your critical functions, create a shortcut navigational system. The system should allow the user to rapidly link to the function or service that he/she seeks without going through all of the intermediate pages. Fleming (1998) lists 5 methods - search function, table of contents, index, site map and pull-down menus. In our experience, a good site map or table of contents will suffice. We find site search tools to be difficult for the average user to employ. (Have you ever tried to find out what fees a financial services firm charges for their services from web sites using their "search function"?)

- $\quad$ Fleming (1998) states that users drill down through three tiers of navigational needs. The first tier contains general questions such as Where am I, and How do I get there? The second tier includes purpose-oriented questions such as How can I find what I want, and What if I'm not exactly sure what I'm looking for? The third tier involves product- or audience-oriented questions such as Where can I get reviews or recommendations, and How do I find out about awards?

Colors and Fonts. In the general layout you need to consider the colors and fonts for your site. Dmitry Kirsanov presents an in depth analysis of the alternatives. Here are some practical rules:

- $\quad$ First, select backgrounds and colors that are not difficult to read. This is particularly true when selecting a background color. Avoid dark or overly bright backgrounds; they often mask the text and graphics. Generally, select a very light (or high contrast color such as white) background and a dark color for text. If you use a background image, then be careful to pick an image that is very subdued and does not repeat itself so often as to become intrusive to the viewer. This tiling effect can really hurt the readability of your site. Use very large images as backgrounds to avoid tiling.

- $\quad$ Second, use color and font changes sparingly and for effect. Also use colors and fonts consistently. One technique for color design is to build your page using black and white and then add color only for emphasis.

- Third, remember that many web browsers can only see 256 colors. Also, all browsers don't have the same 256-color pallet. Today, web browsers only share 216 common colors. You should choose your colors from the common 216-color pallet. 
Graphics. Graphics are an important element of your site. Remember that graphic files are significantly larger than text files - they require more time to download and if your viewer is accessing your site over a dial-up line, the time for download can be disruptive. Much of the work in graphics is thus aimed at reducing the size of the files that have to be downloaded to the viewer's site. However, the key issue is not the file size but the connection speed (Chester and Gingrande, 2001):

- $\quad$ There are two common formats for web graphics - graphic interchange format (GIF) and joint program graphics (jpeg). (Other formats include TIFF, Tagged Image File Format; PNG, Portable Network Graphics; DjVu, Deja Vieux; and PDF, Portable Document Format.) Be judicious in their use: Use GIF formats for most computer generated graphics and graphics from the various draw programs. Use the GIF image format to save images that contain only a few colors or images that contain large areas of the same color such as charts, tables, etc. Use jpeg for photographs.

- When designing graphics there are several things that you can do to reduce the size of the graphic downloads. Reduce the number of colors. Look at your graphic using one of the common graphic packages. Reduce the colors to 256 and look at the graphic; then reduce it to 16 and again look at your graphic. 16 color GIFs require much less data to be downloaded the 256 bit GIFs. Increase the compression levels of jpeg images.

- Use small thumbnail size images and allow users to choose to download a larger version of the image if they desire.

- $\quad$ Combine several smaller images into one larger image. A single large image will load faster than several smaller images.

- Graphics also refers to the overall look and feel of your web site. As mentioned previously, the services of a graphical designer can improve immeasurably the "graphical user interface" or GUI that your site presents to the user. As examples of different designs with different purposes, see Wildbur and Burke (1998) especially pages 98-127.

Corporate Identity. Your web site must reflect a consistent identity tied to your organization. Olins (1989) states that "identity is expressed in the names, symbols, logos, colors ... which the organization uses to distinguish itself, its brands and its constituent companies." Remember that your web site must be tied to your overall organizational identity. Choose logos and colors that are consistent with your total corporate identity. Also understand that to your users, your web presence will be your corporate identity! We suggest that you employ the services of a professional to provide the right logo and colors for your purposes. Honeywell (1999) provides a methodology for evaluating logos and other graphic icons.

Multimedia. A wide assortment of new Web based multimedia tools have emerged in the past several years. These range from animated GIF to Shockwave, Flash and Real Audio/Video. We have all seen the fancy Shockwave or Flash presentations at the beginning of some sites. Most offer the option "Skip Intro" or something similar. It has been our experience that unless such multimedia is directly tied to the purpose of the web site/page, it is not worth the effort. For example, multimedia is a great way to show someone how to do something visually or to provide audio content. It should not, however, be part of the mainstream process:

- $\quad$ Remember that these techniques require data to be downloaded to the viewers' computer (and the viewer has to spend the time waiting). For example, a 1 minute Real Audio file requires about $120 \mathrm{k}$ bytes to be downloaded, while a 30 second Shockwave intro requires about 75k (depending on graphics) To see a large assortment of Shockwave spots, go to their web site.

- $\quad$ These techniques also require that the viewer install some additional software (or plug-in) to properly view your material. These plug-ins are often not compatible with each other.

- $\quad$ Carefully consider the tradeoffs before you adopt one of these techniques in your site. Weigh the added benefits (relative to your intended purpose) versus the loss in viewership (because of increased load times and reluctance to install new plug-ins).

General Layout The general layout system that we recommend is a template built using a grid system that breaks up your page into discrete areas or functions. The template can be initially laid out using ruled paper. The template 
should identify the specific areas for navigation, page identification, content information, logos, etc. The template insures compatibility between pages, i.e., functions are located and sized consistently. The template also allows you to balance the page layout to account for differences in dark/light objects, adjacent colors/forms, text versus graphics, etc. As an alternative, Sano (1996) recommends the use of frames for the same purpose.

\section{Step 14: Test your general design}

Before you actually begin a full-scale implementation of your site, construct and test several prototype pages of your web site to test out your ideas. Nielsen (1999) recommends that web sites be tested with a usability expert as well as real users, and he observes that "most companies use their intuition to develop their web sites; you have to be smart to acknowledge that your own intuition is wrong."

- $\quad$ For large, complex sites, we suggest a minimum of three pages; for smaller sites one or two pages should be sufficient. In building these test pages, don't worry about the copy (text or graphics) in the body of the pages. Concentrate on navigation and general graphics characteristics. Do be sure to build a working copy of your proposed navigational system (the buttons, tabs or whatever, their graphics, placement, etc.) You might try one design for the "master page" - the page that your most important viewers will enter your site and at least one action page - where the viewer orders something or provides you with information input.

- Test your designs out on an audience. It is important that third parties who were not privy to the design review your work. Subject the test pages to the same analysis that your reviewers perform when looking at the competitor's web sites in Substep 1 of Phase 1.

- $\quad$ Powell (1998, pp. 251-267) notes that if the web site involves the user entering data, the data need to be examined for being in the proper format (e.g., ZIP codes must be all numbers) and in the proper range (e.g., a person's age must not be negative).

- An overall test plan should be developed and implemented in order to ensure that all critical aspects of the web site are systematically examined.

- $\quad$ Modify your general layout and iterate the design process.

\section{Step 15: Be prepared to maintain your web site.}

Web site design does not end when the site has been initially designed, developed, and installed. Experience from its use will result in valuable feedback leading to design improvements. Experience from its use will also reveal problems requiring maintenance. Changes in technology will require that the site be updated to accommodate new features, improved software, and better hardware. This step in particular emphasizes the iterative nature of SPUD.

\section{Conclusions}

In this paper we have offered a three phase, 15 step structured methodology called SPUD (for Site-Purpose--User--Design) for the purpose of crafting "good" web sites. This methodology was developed from extensive experience in working with undergraduate and graduate students, in working with companies, in reading the literature, and in developing web sites as webmasters. A companion paper, Tuggle and Slivinski (2001), report on the application of SPUD to the design of web sites for three radically different firms. Experience with the methodology seems to indicate that it is useful in developing useful web sites in an orderly, efficient manner.

\section{References}

1. American Demographics, http://www.marketingtools.com/

2. Betts, M. 2000. Turning browsers into buyers. Sloan Management Review, Vol. 42, No. 2, Winter, 8-9.

3. Blakey, D. 2000. http://www.webdevelopersjournal.com/articles/walkthrough.html

4. Broadbent, S. and F. Cara 2000. A narrative approach to user requirements for Web design. Interactions, 


\section{Table 1.: An Overview of the SPUD Web Site Design Methodology}

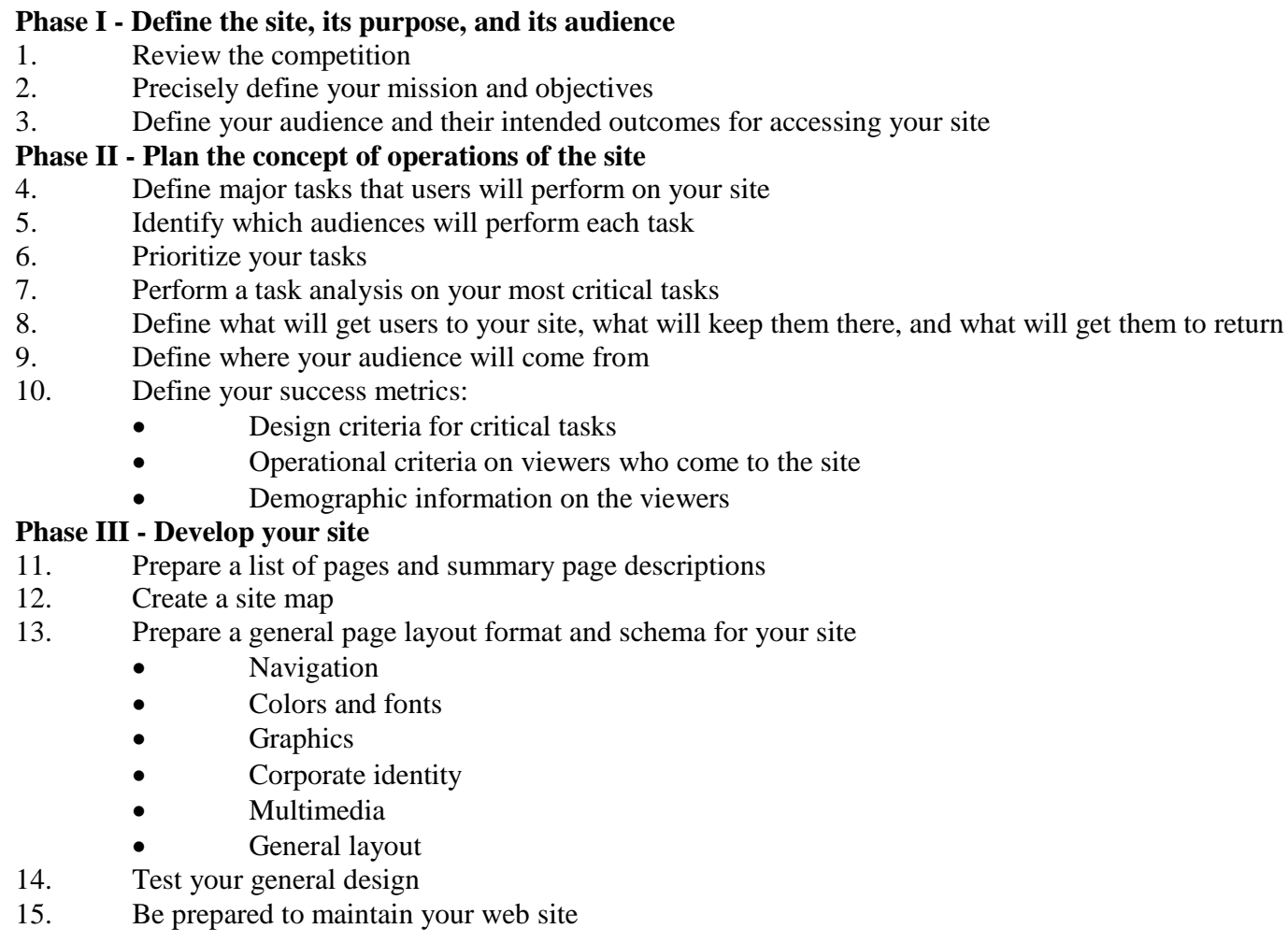

Vol. 7, No. 6, Nov./Dec., pp. 31-35.

5. Chester, B., and A. Gingrande 2001. The puzzling process of publishing images to the web. KMWorld, Vol. 10, No. 1, January, pp. 16, 17, \& 28.

6. Claritas, http://www.qmsoft.com/solutions/prizm.htm

7. Fleming, J. 1998, Web Navigation: Designing the User Experience, Sebastapol, CA, O’Reilly.

8. Freshtech.com,E-BusinessCustomerRetention, http://www.freshtech.com/white_paper/Customer_retention.htm

9. Honeywell, P. 1999. Visual Language for the World Wide Web, Portland, OR, Intellect.

10. Kirsanov, D. http://webreference.com/dlab/

11. Nielsen, J. 1999. Designing Web usability: The practice of simplicity. Indianapolis, IN: New Riders

12. Olins, W. 1989. Corporate identity: Making business strategy visible through design. Boston: Harvard Business School Press.

13. Powell, T. 1998. Web Site Engineering - Beyond Web Page Design. Upper Saddle River, NJ, Prentice Hall.

14. Rosenfeld, L. \& Morville, P. 1998, Information Architecture for the World Wide Web, Sebastapol, CA, O'Reilly

15. Sano, D. 1996. Designing Large-scale Web sites: A visual design methodology. New York: Wiley.

16. Shneiderman, B. 1992. Designing the user interface. $2^{\text {nd }}$ Ed. Reading, Mass: Addison--Wesley.

17. Shockwave, http://www.best.com/ mikesand/ShowHowItWorks3.html\#examples1

18. Tuggle, F. D. and T. Slivinski 2001, The Application of a Structured Methodology for the Design of Web Sites, working paper, Kogod School of Business, American University.

19. Wannacott, L. 2001. Performance issues for e-commerce sites may be lost in the clutter. Infoworld, Vol. 23, No. 4, January 22, p. 57.

20. Wildbur, P., and M. Burke. 1998. Information graphics: Innovative solutions in contemporary design. London: Thames and Hudson. 